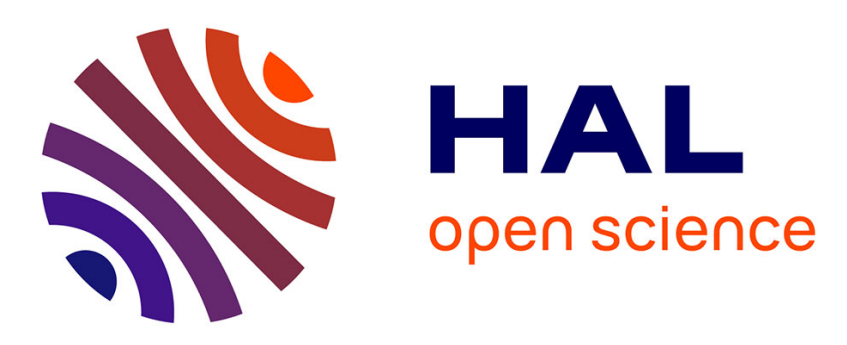

\title{
Rheology and heat transfer during mineral residue phosphatation in a rheo-reactor
}

\author{
Ange Nzihou, Blandine Bournonville, P Marchal, L Choplin
}

\section{To cite this version:}

Ange Nzihou, Blandine Bournonville, P Marchal, L Choplin. Rheology and heat transfer during mineral residue phosphatation in a rheo-reactor. Chemical Engineering Research and Design, 2004, 82 (A5), pp.637-641. 10.1205/026387604323142694 . hal-01634398

\section{HAL Id: hal-01634398 \\ https://hal.science/hal-01634398}

Submitted on 11 Feb 2019

HAL is a multi-disciplinary open access archive for the deposit and dissemination of scientific research documents, whether they are published or not. The documents may come from teaching and research institutions in France or abroad, or from public or private research centers.
L'archive ouverte pluridisciplinaire HAL, est destinée au dépôt et à la diffusion de documents scientifiques de niveau recherche, publiés ou non, émanant des établissements d'enseignement et de recherche français ou étrangers, des laboratoires publics ou privés. 


\title{
RHEOLOGY AND HEAT TRANSFER DURING MINERAL RESIDUE PHOSPHATATION IN A RHEO-REACTOR
}

\author{
A. NZIHOU ${ }^{1, *}$, B. BOURNONVILLE ${ }^{1}$, P. MARCHAL ${ }^{2}$ and L. CHOPLIN ${ }^{2}$ \\ ${ }^{1}$ LGPSD, UMR CNRS 2392, Ecole des Mines d'Albi-Carmaux, Albi, France \\ ${ }^{2}$ GEMICO, ENSIC, Nancy, France
}

\begin{abstract}
$\mathrm{T}$ he rheo-reactor consists of a cylindrical vessel equipped with a double helical ribbon impeller installed in a RS150 controlled stress rheometer. It was used to investigate the rheological behaviour and the heat transfer in aqueous mineral residue suspensions during the phosphatation process. The absolute viscosity was determined using a Couette analogy allowing the quantitative analysis of the torque-rotational speed. The results show that the suspensions exhibit a viscoplastic or Binghamian behavior. The experimental operating conditions for the phosphatation process were then selected in order to ensure a good macromixing, even in laminar regime $(R e<30)$. Heat was generated as the combined result of the exothermic phosphatation process and the viscous dissipation inside the rheo-reactor. The heat produced needed to be efficiently removed to reduce its effect on the behaviour of the suspension. This was evaluated using the Nusselt number and the heat transfer coefficient $h$.
\end{abstract}

Keywords: mineral residue phosphatation; concentrated suspensions; Bingham fluid; rheo-reactor; macromixing; heat transfer.

\section{INTRODUCTION}

The mineral residue phosphatation process is generally carried out in a stirred reactor and aims to produce stable mineral species in which the toxic metals contained in the mineral residue can be trapped, in an insoluble form.

The efficiency of the process depends on the transport phenomena occurring in the reactor which strongly depends on the rheology of the mineral residue concentrated aqueous suspensions. As the exothermic phosphatation reaction proceeds, the rheology of the suspensions leads to further knowledge of the suspension rheology throughout the whole process, which is of crucial importance for ensuring an efficient phosphatation of the mineral residue.

For this purpose, we will make use of the so-called 'rheoreactor' methodology (Choplin and Marchal, 1999) for characterizing the viscous behaviour of the concentrated aqueous mineral residue suspensions in conditions that can mimic the phosphatation process.

More specifically and simultaneously, the rheo-reactor allows us to:

- determine the viscous behaviour of the suspension in nonreacting conditions;

*Correspondence to: Dr A. Nzihou, LGPSD, UMR CNRS 2392, Ecole des Mines d'Albi-Carmaux, Campus Jarlard, Route de Teillet, 81013 ALBI CT Cedex 09, France.

E-mail: ange.nzihou@njit.edu
- realise an in situ viscous follow-up during the phosphatation process (at an effective shear rate related to the imposed stirring conditions);

- impart specific and quantified macromixing and heat transfer conditions during this process.

One of the main advantages of the rheo-reactor methodology relates to the non-settling and relatively well-mixed conditions under which the viscous measurements are made, provided the geometrical configuration used is a vessel agitated with an helical ribbon impeller claimed as an efficient 'mixer' for viscous and non-Newtonian suspensions. In this geometry, the suspension remains pseudo-homogeneous and a correct viscosity value can be determined directly from the torque measured on the impeller shaft.

In this paper, we will examine preliminary results on the viscous behaviour of mineral residue suspensions at different volume or mass fractions as influenced by the phosphatation reaction.

\section{MATERIALS AND METHODS}

Mineral residues obtained from a municipal solid waste incinerator contained water-soluble salts. The salts were extracted in demineralized water in a 1001 laboratory reactor. The liquid phase extract was filtered and evaporated in order to determine the water-soluble content. The solid fraction of mineral residues without the salts was used in aqueous suspensions (with a solid mass fraction $\mathrm{X}$ varying 
from 20 up to $45 \%$ ) as samples for the experiments described in this paper.

Mineral residue particle mean size of $28 \mu \mathrm{m}$ was determined with a Mastersizer laser granulometer (Malvern Instruments). This value may in fact correspond to the mean size of aggregates. The mineral residue density $\left(\rho_{\mathrm{p}}\right)$ of $2460 \mathrm{~kg} \mathrm{~m}^{-3}$ was determined with a Micromeritics 1330 gas pycnometer.

The mineral residue specific surface area of $15.8 \mathrm{~m}^{2} \mathrm{~g}^{-1}$ was obtained though a classical BET method with a Gemini Micromeritics instrument. The heat capacity $C_{\mathrm{p}}=246 \mathrm{~J} \mathrm{~K}^{-1} \mathrm{~kg}^{-1}$ was evaluated at $30^{\circ} \mathrm{C}$ with a Calvet C80 calorimeter (Setaram) and the thermal conductivity $\lambda=0.118 \mathrm{~W} \mathrm{~m}^{-1} \mathrm{~K}^{-1}$ was estimated using the hot disc method. The mineral residue composition was as follows: $\mathrm{Al}_{2} \mathrm{O}_{3}(17 \%), \mathrm{CaO}(25 \%), \mathrm{Fe}_{2} \mathrm{O}_{3}(2 \%), \mathrm{SiO}_{2}(28 \%), \mathrm{SO}_{4}(2$ $\%), \mathrm{Cr}(513 \mathrm{ppm}), \mathrm{Cu}(1022 \mathrm{ppm}), \mathrm{Pb}$ (3731 ppm) and $\mathrm{Zn}$ $(12,417 \mathrm{ppm})$.

Phosphoric acid ( $>85 \mathrm{wt} \%$ Normapur, Prolabo) was used for the phosphatation reaction with a concentration of $12 \mathrm{wt} \%$. The correspondence between mass and volume fraction is given in Table 1 . The values were calculated according to the following equation which defines the solid volume fraction as the ratio between the volume of solid particles and the volume of the suspension:

$$
\phi=\frac{V_{\mathrm{p}}}{V}=\frac{V_{\mathrm{p}}}{V_{\mathrm{p}}+V_{\mathrm{s}}}=\frac{X / \rho_{\mathrm{p}}}{\left(X / \rho_{\mathrm{p}}\right)+\left[(1-X) / \rho_{\mathrm{s}}\right]}
$$

in which $\rho_{\mathrm{s}}$ is the density of the suspending fluid.

Previous work by Bournonville and Nzihou (2002) established that the volume fraction should not exceed $33 \%$. The rheo-reactor consists of a cylindrical vessel equipped with a double helical ribbon impeller (see Figure 1) with a capacity of almost $175 \mathrm{ml}$ and was installed in an RS150 controlled stress rheometer (Haake).

An analytical method based on a Couette analogy (Ait-Kadi et al., 2002) allowed quantitative analysis of the torque-rotational speed data of the rheometer in order to extract absolute viscosity-shear rate data in non-conventional geometries, in particular that used in this paper. The Couette analogy assumes that the rheo-reactor geometry (cylindrical vessel equipped with a helical-ribbon impeller) is equivalent to a concentric cylinder geometry, in which the height, $H$, and the external radius, $R_{\mathrm{e}}$, remain unchanged. The internal radius, $R_{\mathrm{i}}$, in this equivalent geometry is chosen in order to give, in both geometries, the same torque, $T$, for the same rotational speed, $N$, imposed on the impeller and/or the internal cylinder, for the same fluid. This internal radius, $R_{\mathrm{i}}$, can be calculated analytically (in the concentric Couette geometry) assuming laminar steady state and isothermal conditions and solving the equations of change for a

Table 1. Calculation of volume fraction of solids using the mass fraction.

\begin{tabular}{lc}
\hline Mass fraction, $X(\%)$ & Volume fraction, $\phi(\%)$ \\
\hline 20 & 9 \\
25 & 12 \\
30 & 15 \\
35 & 18 \\
40 & 21 \\
45 & 25 \\
\hline
\end{tabular}

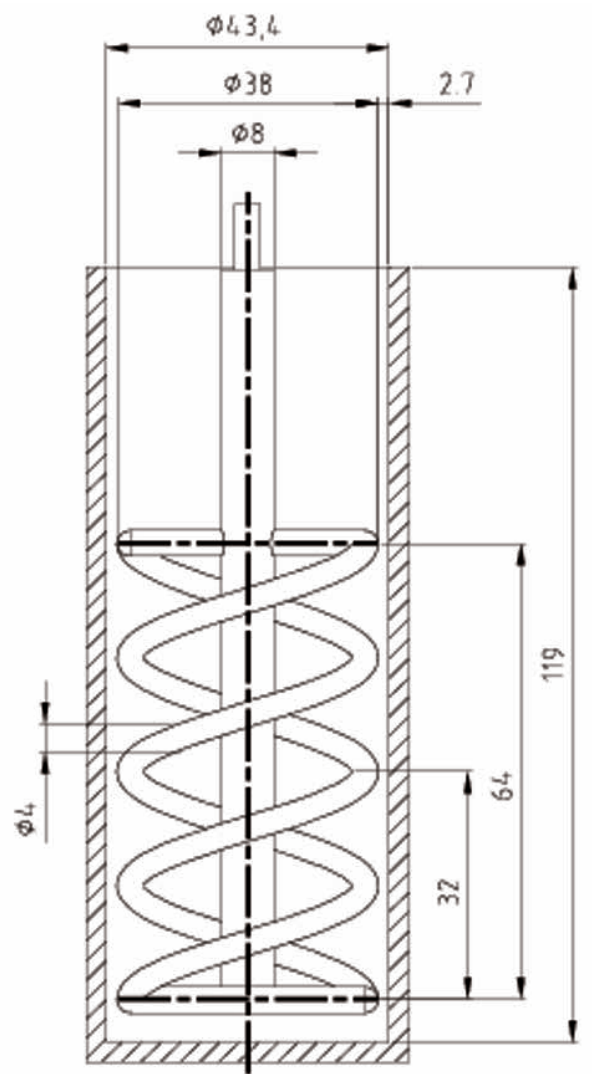

Figure 1. Rheo-reactor equipped with a helical-ribbon impeller.

power-law fluid (such an assumption is not restrictive at all over a limited shear rate range). We obtain:

$$
R_{i}=\frac{R_{\mathrm{e}}}{\left[1+(4 \pi N / n)\left(2 \pi k H R_{\mathrm{e}}^{2} / T\right)^{1 / n}\right]^{n / 2}}
$$

in which $n$ and $k$ are the parameters of the power-law model, relating the apparent viscosity, $\mu$, to the shear rate, $\dot{\gamma}$, according to the following expression:

$$
\mu=k \dot{\gamma}^{n-1}
$$

where $n$ is the power law index and $k$ is the consistency index (in $\mathrm{Pa} \mathrm{s}^{n}$ ).

For a given set of $(N, T)$ values, it is found that $R_{\mathrm{i}}$ is a weak function of $n$, therefore the determination of $R_{\mathrm{i}}$ can be carried out in the particular case of $n=1$, that is with a Newtonian fluid of known viscosity.

The second step concerns the calculation of the shear stress and the shear rate at a given position in the gap of the virtual Couette geometry. The shear stress is given by:

$$
\tau=\frac{T}{2 \pi H r^{2}}
$$

and the shear rate, for a power-law fluid, is

$$
\dot{\gamma}=\left[\frac{(4 \pi / n)\left(R_{\mathrm{i}} / r\right)^{2 / n}}{1-\left(R_{\mathrm{i}} / R_{\mathrm{e}}\right)^{2 / n}}\right] N
$$

Even for a virtual gap, we found that there is a specific position, $r^{*}$, in the gap for which the term in brackets in equation (5) is essentially independent of the power-law index $n$, in other words, the rheology of the fluid. Once 
this $r^{*}$ value has been determined for the particular case of $n=1$, we can evaluate the viscosity at an effective shear rate, $\dot{\gamma}_{r^{*}}$, using the following expression:

$$
\mu=\frac{\tau_{r^{*}}}{\dot{\gamma}_{r^{*}}}=\frac{T /\left(2 \pi H r^{* 2}\right)}{4 \pi N\left(R_{i} / r^{*}\right)^{2} /\left[1-\left(R_{\mathrm{i}} / R_{\mathrm{e}}\right)^{2}\right]}
$$

In our particular case and taking into account the specific geometry of the rheo-reactor, equation (6) becomes:

$$
\mu=\frac{\tau_{r^{*}}}{\dot{\gamma}_{r^{*}}}=\frac{K_{\tau} T}{K_{\dot{\gamma}} N}=\frac{6450 T}{40 N}
$$

in which $N$ is given in rps and $T$ in $\mathrm{Nm}$.

It should be mentioned here that $K_{\dot{\gamma}}$ is nothing but a $K_{\mathrm{s}}$ value, known as the Metzner-Otto constant (Metzner and Otto, 1957). This numerical value agrees fairly well with experimental values available in the literature for this impeller-vessel configuration (Chavan et al., 1972; Chavan and Ulbrecht 1973; Kemblowski et al., 1988; Carreau et al., 1993; Brito de la Fuente et al., 1997), although slightly higher than an accepted value (Delaplace et al., 2000). This may be due to the specific geometric configuration of the vessel agitator arrangement.

\section{RESULTS AND DISCUSSION}

Figure 2 reports the viscosity as a function of the shear rate for the different mineral residue suspensions studied. At low shear rates, the slope of the viscosity curves approaches a $(-1)$ value, which indicates the presence of a yield stress, $\tau_{0}$. Because of plateau viscosity values at high shear rates, the viscous behaviour can be assumed to be viscoplastic or Binghamian, and can be represented by the following Bingham model:

$$
\mu=\mu_{\infty}+\frac{\tau_{0}}{\dot{\gamma}}
$$

in which $\mu_{\infty}$ is the plastic viscosity.

The range of shear rates examined was dictated by the experimental conditions that could be imposed in the rheoreactor during the phosphatation process. Figure 3 shows the viscosity as a function of the shear rate for the different mineral residue suspensions studied after premixing with $12 \mathrm{wt} \%$ phosphoric acid and around 2 min of elapsed reaction time, which corresponds roughly to an $80 \%$ conversion.

The viscous behaviour is very similar although slightly more viscous compared with that shown in Figure 2. The

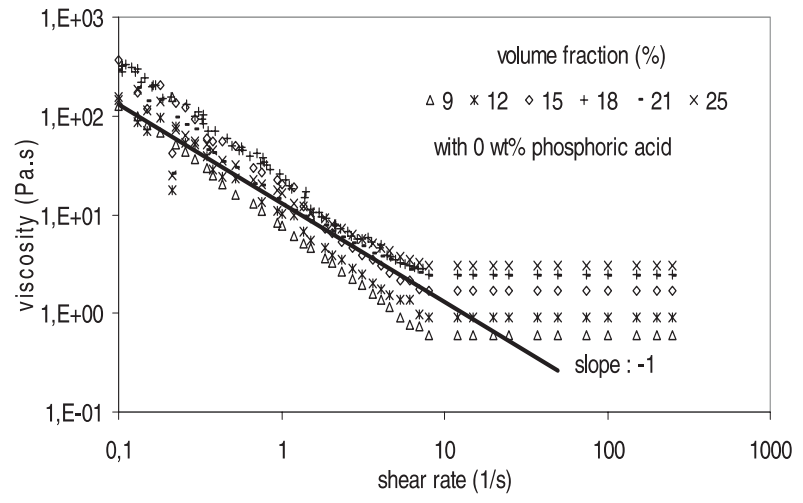

Figure 2. Shear viscosity versus shear rate for non-reactive suspension.

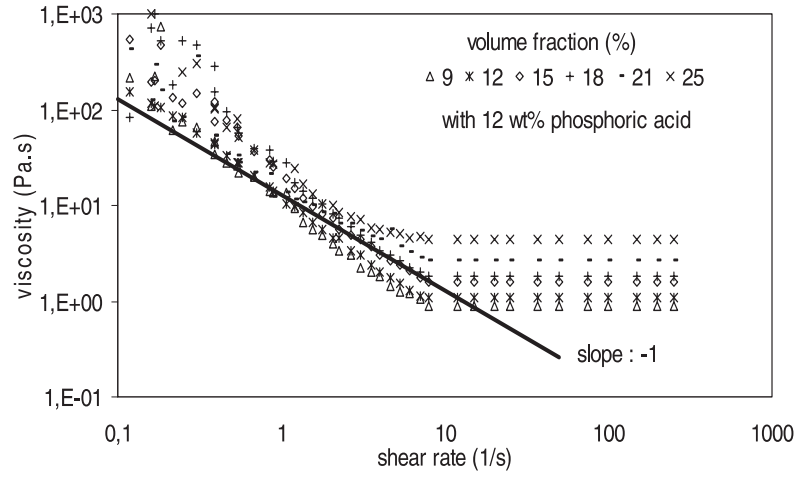

Figure 3. Shear viscosity versus shear rate for reactive suspension with $12 \mathrm{wt} \%$ phosphoric acid.

parameters of the Bingham model for all cases are reported in Table 2.

To bring in motion (and therefore mixing) in the entire reactor, the shear stress everywhere in the reactor must be maintained above the yield stress value, $\tau_{0}$. The plastic viscosity, $\mu_{\infty}$, which times the effective shear rate, is more important than the shear stress, $\tau_{\text {eff. }}$ The effective shear rate is expressed using the following relationship:

$$
\dot{\gamma}_{\text {eff }}=K_{\dot{\gamma}} N
$$

Therefore, we must have:

$$
\tau_{\text {eff }}=\mu_{\infty} \dot{\gamma}_{\text {eff }}=\mu_{\infty} K_{\dot{\gamma}} N \gg \tau_{0}
$$

This is equivalent to writing:

$$
B i=\frac{\tau_{\text {eff }}}{\tau_{0}} \gg 1
$$

where $B i$ is the Bingham number. In order to respect this condition we have chosen a rotational speed $N$ of $400 \mathrm{rpm}$ (=6rps), which corresponds to an effective shear rate of $240 \mathrm{~s}^{-1}$.

Under these operating conditions, the fluid inside the entire reactor can be considered as equivalent to a Newtonian fluid with a viscosity equal to the plastic viscosity $\mu_{\infty}$. Therefore the dimensionless number for characterizing the hydrodynamics in the phosphatation

\begin{tabular}{|c|c|c|c|c|}
\hline \multirow[b]{2}{*}{$\begin{array}{l}\text { Volume } \\
\text { fraction }(\%)\end{array}$} & \multicolumn{2}{|c|}{$\begin{array}{c}0 \mathrm{Wt} \% \\
\text { phosphoric acid }\end{array}$} & \multicolumn{2}{|c|}{$\begin{array}{c}12 \mathrm{Wt} \% \\
\text { phosphoric acid }\end{array}$} \\
\hline & $\begin{array}{l}\tau_{0} \\
(\mathrm{~Pa})\end{array}$ & $\begin{array}{c}\mu_{\infty} \\
(\mathrm{Pa} \mathrm{s})\end{array}$ & $\begin{array}{c}\tau_{0} \\
(\mathrm{~Pa})\end{array}$ & $\begin{array}{c}\mu_{\infty} \\
(\mathrm{Pa} \mathrm{s})\end{array}$ \\
\hline 9 & 14.5 & 0.6 & 20.5 & 0.9 \\
\hline 12 & 18.5 & 0.9 & 25.7 & 1.1 \\
\hline 15 & 33.9 & 1.7 & 50.1 & 1.6 \\
\hline 18 & 45.7 & 2.5 & 50.2 & 1.8 \\
\hline 21 & 36.9 & 2.4 & 54.4 & 2.6 \\
\hline 25 & 32.9 & 3.0 & 60.8 & 4.4 \\
\hline
\end{tabular}
process reactor is the Reynolds number, defined as:

$$
R e=\frac{\rho N d^{2}}{\mu_{\infty}}
$$

Table 2. Bingham model parameters of mineral residue suspension. 
Table 3. Heat transfer coefficient of mineral residue suspension.

\begin{tabular}{lcccrc}
\hline $\begin{array}{l}\text { Volume } \\
\text { fraction, } \\
\phi(\%)\end{array}$ & 0.5 & 5 & 25 & 100 & 240 \\
\cline { 2 - 6 } & 192 & 415 & 709 & 1126 & 1507 \\
\hline 9 & 186 & 401 & 685 & 1088 & 1457 \\
12 & 179 & 386 & 660 & 1047 & 1402 \\
15 & 172 & 370 & 632 & 1004 & 1344 \\
18 & 164 & 353 & 604 & 958 & 1283 \\
21 & 156 & 335 & 573 & 910 & 1218 \\
25 & & & & & \\
\hline
\end{tabular}

in which $d$ is the diameter of the impeller. In all experiments, $R e$ never exceeded the upper limit of laminar regime, and remained below 30 .

Furthermore, inside the rheo-reactor, heat is produced by the exothermic reaction and also by viscous dissipation. In fact, regarding the level of apparent viscosity of the suspensions in Figure 3, the viscous dissipation, which is the work done in the suspension by the ribbon impeller against viscous forces, is irreversibly converted into internal energy (heat) that could be significant (Xu et al., 2003; Bird et al., 1960). That heat must be efficiently removed. In this paper, the investigation of heat transfer is considered as the combined effects of the phosphatation process and viscous dissipation.

The enthalpy of the processes considered is $685 \mathrm{~kJ} \mathrm{~mol}_{\mathrm{H} 3 \mathrm{PO} 4}{ }^{-1}$ and it corresponds to a temperature increase of about $10^{\circ} \mathrm{C}$ during the reaction (Bournonville, 2002). The heat removal can be evaluated through the calculation of the heat transfer coefficient, $h$, using the following Nusselt number correlation proposed by Mitsuishi and Miyairi (1973) for a laminar regime and for a stirred reactor almost equivalent to that used in this study:

$$
N u=\frac{h d}{\lambda}=0.78 \operatorname{Re}^{1 / 3} \operatorname{Pr}^{1 / 3}\left(\frac{\mu}{\mu_{\mathrm{w}}}\right)^{0.18}
$$

in which $\operatorname{Pr}=C_{\mathrm{p}} \mu_{\infty} / \lambda$ is the Prandtl number and $\mu_{\mathrm{w}}$ is the viscosity of the suspension at the wall temperature. Provided the reactor may operate under well-mixed conditions, the temperature in the small volume rheo-reactor can be considered as a constant and we can omit the last term in equation (13).

The heat transfer coefficients calculated from the Nusselt number [equation (13)] are reported in Table 3, showing a variation of an order of magnitude between 156 and $1507 \mathrm{~W} \mathrm{~m}^{-2} \mathrm{~K}^{-1}$. Convection appears to be the dominant heat transfer process. In the operating conditions we have used, the heat transfer coefficient is quite high, favouring therefore heat removal, and slightly decreases with the increasing volume fraction of solids in the suspension.

\section{CONCLUSIONS}

Concentrated mineral residue aqueous suspensions were characterized from a viscous point of view in a rheo-reactor and exhibited a viscoplastic (Bingham) behaviour over the range of concentrations studied.

The knowledge of the viscous behaviour allowed us to select appropriate operating conditions to realize an efficient phosphatation reaction under well-mixed/non-settling conditions with good heat removal in this rheo-reactor. It has been shown that the viscous behaviour varied slightly with the conversion during the phosphatation reaction. Further work will focus on mass transfer and scale-up of this process.

\section{NOMENCLATURE}

\begin{tabular}{|c|c|}
\hline$B i$ & Bingham number \\
\hline$C_{\mathrm{p}}$ & heat capacity, $\mathrm{J} \mathrm{K} \mathrm{kg}^{-1}$ \\
\hline$e$ & clearance between impeller and vessel wall, $\mathrm{m}$ \\
\hline$h$ & heat transfer coefficient, $\mathrm{W} \mathrm{m}^{-2} \mathrm{~K}^{-1}$ \\
\hline$H$ & height of the cylinder, $\mathrm{m}$ \\
\hline$k$ & constant \\
\hline$K_{\mathrm{s}}$ & Metzner-Otto constant \\
\hline$K_{\tau}$ & stress constant, $\mathrm{Pa} \mathrm{N}^{-1} \mathrm{~m}^{-1}$ \\
\hline$K_{\dot{\gamma}}$ & shear rate constant, $1 \mathrm{rad}^{-1}$ \\
\hline$n$ & consistency \\
\hline$N$ & impeller rotational speed, $\mathrm{s}^{-1}$ \\
\hline $\mathrm{Nu}$ & Nusselt number \\
\hline $\operatorname{Pr}$ & Prandlt number \\
\hline$r^{*}$ & specific position in the gap, $m$ \\
\hline $\operatorname{Re}$ & Reynolds number \\
\hline$R$ & couette cylinder radius, $\mathrm{m}$ \\
\hline$T$ & torque, $\mathrm{Nm}$ \\
\hline$V$ & volume, $\mathrm{m}^{3}$ \\
\hline$X$ & mass fraction of solid, $\%$ \\
\hline \multicolumn{2}{|c|}{ Greek symbols } \\
\hline$\dot{\gamma}$ & shear rate, $\mathrm{s}^{-1}$ \\
\hline$\dot{\gamma}_{\text {eff }}$ & effective shear rate, $\mathrm{s}^{-1}$ \\
\hline$\rho$ & density, $\mathrm{kg} \mathrm{m}^{-3}$ \\
\hline$\lambda$ & thermal conductivity, $\mathrm{W} \mathrm{m}^{-1} \mathrm{~K}^{-1}$ \\
\hline$\mu$ & viscosity, Pas \\
\hline$\mu_{\infty}$ & plastic viscosity, $\mathrm{Pa}$ s \\
\hline$\tau_{0}$ & yield stress, $\mathrm{Pa}$ \\
\hline$\phi$ & volume fraction of particles \\
\hline \multicolumn{2}{|c|}{ Subscripts } \\
\hline e & external \\
\hline eq & equivalent \\
\hline eff & effective \\
\hline $\mathrm{i}$ & internal \\
\hline $\mathrm{p}$ & particle \\
\hline s & continuous phase \\
\hline $\mathrm{w}$ & wall \\
\hline
\end{tabular}

\section{REFERENCES}

Ait-Kadi, A., Marchal, P., Choplin, L., Chrissemant, A.S. and Bousmina, M., 2002, Quantitative analysis of mixer-type rheometers using Couette analogy, Can J Chem Eng, 80(6): 1166-1174.

Bird, R.B., Stewart, W.E. and Lightfoot, E.N., 1960, Transport Phenomena (Wiley, New York, USA).

Bournonville, B., 2002, Stabilisation des métaux lourds dans les cendres volantes d'incinération-comportement rhéologique, cinétique de phosphatation et évaluation du procédé, $\mathrm{PhD}$ thesis, Université de Perpignan.

Bournonville, B. and Nzihou, A., 2002, Rheology of non-newtonian suspensions of fly ash: effect of concentration, yield stress and hydrodynamic interactions, Powder Technol, 128(2-3): 148-158.

Brito de la Fuente, E., Choplin, L. and Tanguy, P., 1997, Mixing with helical ribbon impellers. Effect of highly shear-thinning behavior and impeller geometries, Trans IChemE, Part A, Chem Eng Res Des, 75(A): 45-52.

Carreau, P.J., Chhabra, R.P. and Cheng, J., 1993, Effect of rheological properties on power consumption with helical ribbon agitators, AIChE $J, 39(9)$ : 1421-1429.

Chavan, V.V. and Ulbrecht, J., 1973, Power correlations for close-clearance helical impellers in non-Newtonian liquids, Ind Eng Chem Process Des Dev, 14(4): 472-476.

Chavan, V.V., Jhaveri, A.S. and Ulbrecht, J., 1972, Power consumption for mixing of inelastic non-Newtonian fluids by helical screw agitators, Trans IChemE, 50: 147-155.

Choplin, L. and Marchal, P. 1999, Rheo-reactor for in situ rheological followup of chemical or physical processes, Ann Trans Nordic Rheol Soc, 7: 5-12.

Delaplace, G., Leuliet, J.C. and Relandeau, V., 2000, Circulation and mixing times for helical ribbon impellers-review and experiments, Exp Fluids, 28(2): 170-182. 
Kemblowski, Z., Sek, J. and Budzynski, P., 1988, The concept of a rotational rheometer with helical screw impeller, Rheol Acta, 27: 82-90.

Metzner, A.B. and Otto, R.E., 1957, Agitation of non-Newtonian fluids, AIChE J, 3(1): 3-10.

Mitsuishi, N. and Miyairi Y., 1973, Heat transfer to non-Newtonian liquids in an agitated vessel, J Chem Eng Jap, 6: 415-420.

Xu, B., Ooi, K.T., Mavriplis, C. and Zaghloul, M.E., 2003, Evaluation of viscous dissipation in liquid flow in microchannels, $J$ Micromech Microeng, 13: 53-57.

\section{ACKNOWLEDGEMENTS}

Financial support provided by the Health Safety Environment Department of the SOLVAY Group is gratefully acknowledged.

This paper was presented at 9th Congress of the French Society of Chemical Engineering held in Saint-Nazaire, France, 9-11 September 2003. The manuscript was received 10 March 2003 and accepted for publication after revision 6 January 2004. 